\title{
Defined Adverse Event Category Code
}

National Cancer Institute

\section{Source}

National Cancer Institute. Defined Adverse Event Category Code. NCI Thesaurus. Code C95355.

A coded value specifying a defined adverse event category. 